\title{
Editorial
}

\section{Los retos de las revistas científicas de Honduras}

\author{
The challenges of the scientific journals in Honduras \\ Reyna M. Durón ${ }^{1}$ \\ Editora Asociada
}

A pesar de las limitaciones y barreras, la investigación científica hondureña continúa tomando fuerza en áreas y disciplinas muy variadas. Los científicos hondureños publican en revistas indizadas internacionales haciendo aportes importantes en diversas ramas de la ciencia, especialmente en ciencias de la salud, biología, ingeniería, agricultura y ciencias sociales.

Sin embargo, se debe volver la mirada hacia la publicación en revistas locales. Los criterios internacionales de ranking de instituciones universitarias ahora consideran la calidad de sus revistas. Cada vez hay más exigencia de una modernización de las revistas hondureñas, esperando que integren más revisiones por pares externos, combate a la endogamia, uso de plataformas como Open Journal System, publicación puntual con acceso abierto y más estrategias de visibilidad. La tarea no es pequeña y el primer reto es asegurar más apoyo institucional. La primera publicación científica hondureña fue la Revista del Archivo y Biblioteca Nacional, la cual vio la luz en 1906 y se ha seguido publicando por décadas. Posteriormente surgieron otras, sumando 59 revistas según nuestros registros (CONCAPAN IEEE 2019, en prensa). Obviamente, la mayoría son publicadas por universidades. Más de la mitad continúa vigente, pero ninguna ha sido indizada en bases de revistas de exigencia máxima, como SciELO o Scopus.

Por ello, el reto siguiente es estructurar mejor o reforzar los comités y los sistemas editoriales. Los procesos de revisión y edición deberán volverse más rigurosos para cumplir con los más altos estándares científicos y editoriales. Este proceso de reingeniería de revistas requiere capacitación, trabajo en equipo y asesoría de expertos. En este sentido, es muy alentador que ya existen algunos avances para la conformación de un Capítulo SciELO en Honduras y para la integración de un grupo de editores de revistas científicas hondureñas. Con un trabajo armonizado entre universidades y otras editoriales, se podrá lograr mejores resultados para todos. Con la internacionalización de estándares y la práctica de otras medidas locales tomadas en consenso por los editores de Honduras, se podría motivar a más investigadores a publicar en revistas locales, contribuyendo a su mérito y a su calidad. Hasta hace pocos años, la publicación local no parecía ventajosa para los rankings de universidades y de los investigadores. En parte, no se ha valorado el aporte que agrega la visibilidad de estas publicaciones locales en la web y en el aumento de las citaciones que puede generar. Actualmente, la inclusión de criterios sobre publicación local ya es valorada por rankings como Scimago.

En una era de economía del lenguaje, otro reto importante es asegurar la calidad en el uso del castellano y también del inglés. La necesidad de aumentar la visibilidad de la ciencia en un mundo global hace que los investigadores publiquen en otros idiomas, especialmente en inglés. Varias revistas latinoamericanas ya publican artículos bilingües. Ya no sólo vemos el inglés en los resúmenes, sino que también en los textos completos.

Otros retos que enfrentan las revistas hondureñas tienen que ver con la calidad de manuscritos, la disponibilidad de revisores temáticos, metodológicos y estadísticos, la capacitación de revisores locales, los retrasos de publicación por falta de artículos originales, la sostenibilidad y la socialización de las publicaciones. Estos retos también pueden enfrentarse en equipo. Las revistas científicas hondureñas son parte del patrimonio cultural de país y su futuro es prometedor si se aborda los retos con estrategia. Enhorabuena por Innovare, que ha dado pasos hacia el futuro.

\footnotetext{
${ }^{1}$ Autora corresponsal: reyna.duron@unitec.edu.hn, Dirección de Investigación, UNITEC, Campus Tegucigalpa, Honduras 